\title{
GAMBARAN PROSES PENERIMAAN SAUDARA KANDUNG PENYANDANG DISABILITAS INTELEKTUAL
}

\author{
Stephanie Cindy, \\ Shanty Sudarji ${ }^{1}$ \\ Fakultas Psikologi \\ Universitas Bunda Mulia \\ Jl. Lodan Raya No. 2 \\ Jakarta Utara 14430, Indonesia \\ 'e-mail: ssudarji@bundamulia.ac.id
}

\begin{abstract}
Intellectual disability is a developmental disorder which is characterized by deficiency in the mental processing. This deficit leads to the inability in adaptation, which makes individuals unable to fulfill their own living standard and social responsibilities in many aspects of life. Siblings play an important role in the development of children diagnosed with intellectual disability. The existence of children with intellectual disability could affect their sibling in positive or negative way. The purpose of this research was to illustrate the siblings' acceptance regarding their siblings whom were diagnosed with intellectual disability, the factors that affect their acceptance, and the process of how the acceptance formed. This qualitative study used phenomenological approach by doing observation and interview to the responsdents. This research was conducted on five adolescents (1518 years old) whose sibling diagnosed with intellectual disability. The result of this research showed that three subjects have reached the acceptance phase, while two other subjects have not reached acceptance phase. This research also indicates good family communication, proper knowledge, and positive perception regarding intellectual disability as several factors that affect three successful subjects to reach the acceptance phase.
\end{abstract}

Keywords: sibling acceptance; intellectual disability

Abstrak - Disabilitas intelektual merupakan gangguan selama periode perkembangan yang ditandai dengan kurangnya kemampuan mental secara umum. Akibat dari kurangnya kemampuan ini adalah gangguan dalam beradaptasi, sehingga individu gagal memenuhi standar kemandirian pribadi dan tanggung jawab sosial dalam satu atau lebih aspek kehidupan sehari-hari. Saudara kandung berperan penting bagi perkembangan anak yang menyandang disabilitas intelektual. Hadirnya anak yang menyandang disabilitas intelektual dapat memengaruhi secara positif ataupun negatif kehidupan dari saudara kandungnya. Tujuan dari penelitian ini adalah untuk mengetahui gambaran mengenai penerimaan saudara kandung penyandang disabilitas intelektual, faktor-faktor yang memengaruhi penerimaan, dan proses dari penerimaan saudara kandung tersebut. Penelitian ini menggunakan 
metode penelitian kualitatif jenis fenomenologi dengan metode observasi dan wawancara untuk mengumpulkan data. Penelitian dilakukan kepada lima remaja berusia 15-18 tahun dan memiliki saudara kandung penyandang disabilitas intelektual. Hasil penelitian ini menunjukkan bahwa tiga subjek telah mencapai tahap acceptance, sementara dua subjek lainnya belum dapat mencapai tahap acceptance. Subjek yang telah mencapai tahap acceptance dipengaruhi oleh beberapa faktor yaitu, komunikasi yang baik dalam keluarga, memiliki pengetahuan dan informasi mengenai disabilitas intelektual, dan persepsi postitif terhadap penyandang disabilitas intelektual.

Kata Kunci: penerimaan saudara kandung; disabilitas intelektual

\section{PENDAHULUAN}

Disabilitas intelektual, sebelumnya dikenal dengan retardasi mental, merupakan gangguan selama periode perkembangan (Medina, 2016). Disabilitas intelektual ditandai dengan kurangnya kemampuan mental secara umum seperti penalaran, pemecahan masalah, perencanaan, berpikir abstrak, akademik, dan belajar dari pengalaman. Akibat dari kurangnya kemampuan ini adalah gangguan dalam beradaptasi sehingga individu gagal memenuhi standar kemandirian pribadi dan tanggung jawab sosial dalam satu atau lebih aspek kehidupan sehari-hari, termasuk komunikasi, partisipasi sosial, akademik atau pekerjaan, ataupun kemandirian (American Psychiatric Association [APA], 2013). Penyebab disabilitas intelektual yang paling umum adalah kondisi genetik, masalah selama kehamilan, permasalahan ketika kelahiran, dan permasalahan kesehatan yang umum (Algozzine \& Ysseldyke, 2006).

Disabilitas intelektual memiliki tiga kategori, yaitu mulai dari taraf ringan hingga berat. Individu dengan kategori taraf ringan memiliki rentang IQ 50-55 sampai sekitar 70, memiliki kemampuan membaca dan aritmatika sampai kelas 3-6 SD. Individu dalam kelompok taraf sedang memiliki tingkat IQ 35-40 sampai 50-55 mampu mempelajari komunikasi sederhana, keterampilan tangan yang sederhana, perawatan diri yang mendasar, pada tingkatan ini anak masih dapat dibimbing dan dilatih untuk dapat befungsi di dalam lingkungan sosial. Pada taraf berat, individu biasanya memiliki rentang IQ 20-25 sampai 35-40 biasanya mampu berjalan tetapi memiliki ketidakmampuan yang spesifik, pada taraf ini seseorang masih dapat mengerti pembicaraan dan memberikan respons, akan tetapi tidak mengalami kemajuan dalam kemampuan membaca dan aritmatika (Lisnawati, Shahib, \& Wijayanegara, 2014).

Hadirnya anak dengan disabilitas menyebabkan stres untuk orangtua dan anggota keluarga yang lainnya. Umumnya anak dengan disabilitas intelektual memerlukan perhatian lebih dari orangtua dan juga saudara yang lain. Sementara saudara sekandung dari anak dengan disabilitas 
intelektual tersebut seringkali tersisihkan dalam hal perhatian. Dalam proses ini, saudara kandung juga harus dipertimbangkan sama seperti orangtua. Ini merupakan situasi yang sulit bagi seorang anak untuk memiliki saudara yang disabilitas (Aytekin, 2016). Anak yang tidak menyandang disabilitas intelektual harus menyesuaikan diri dengan kondisi saudara mereka karena kondisi saudara mereka yang memerlukan sebagian besar waktu keluarga, perhatian, uang, dan dukungan psikologis. Reaksi anak terhadap saudaranya yang menyandang disabilitas intelektual dapat memengaruhi perkembangan dan penyesuaian diri keduanya (National Dissemination Center for Children with Disabilities [NICHCY], 2017). Saudara kandung memiliki peran penting dalam perkembangan satu sama lain, karena mereka mengobservasi, dan belajar dari perilaku saudaranya (Aytekin, 2016).

Memiliki saudara dengan disabilitas dapat memberikan tantangan emosional dan perilaku (Aytekin, 2016). Hadirnya saudara dengan disabilitas dapat memberikan pengaruh yang positif maupun yang negatif bagi anak yang tidak menyandang disabilitas intelektual. Respons dan perasaan yang ditunjukkan oleh anak terhadap saudaranya yang disabilitas bukan merupakan sesuatu yang bersifat statis melainkan dipengaruhi oleh usia dan tingkat perkembangannya (NICHCY, 2017). McHale dan Gamble (dalam NICHCY, 2017) menyatakan bahwa anak usia sekolah hingga remaja awal memiliki respons dan dampak yang lebih positif. Sementara bagi usia yang lebih besar, respons dan perasaannya cenderung cemas pada masa depan, seperti akan menjadi apa saudara mereka yang menyandang disabilitas, bagaimana pandangan orang-orang terdekat mereka dalam hal ini teman dan pacar, akankah orang lain dapat menerima kondisi saudaranya yang menyandang disabilitas dan mereka mencemaskan mengenai tanggung jawab mereka untuk mengurus saudaranya yang menyandang disabilitas (NICHCY, 2017). Stres yang dirasakan oleh saudara kandung dari anak dengan disabilitas intelektual biasanya lebih tinggi, bukan saja karena tingkah laku dari saudaranya yang berkebutuhan khusus, tetapi juga perbedaan pola pengasuhan orangtua dan adanya tanggung jawab tambahan yang dibebankan kepada mereka.

Penelitian terbaru menunjukkan bahwa selain menimbulkan stres, kehadiran anak-anak disabilitas intelektual dalam keluarga tidak selalu menimbulkan hal yang negatif. Kehadiran anak dengan disabilitas intelektual dapat membantu orangtua dan saudara menjadi dapat lebih memecahkan masalah dengan kreatif, Saudara kandung dari anak disabilitas intelektual dapat lebih menghargai nilai-nilai perbedaan, dan lebih memahami perbedaan antar manusia (Kutner, 2016). Pentingnya peran saudara kandung serta penuturan psikolog, beberapa orangtua, dan beberapa saudara kandung dari penyandang disabilitas intelektual mengenai adanya saudara kandung yang menolak dan saudara kandung yang sedari awal telah menerima kondisi saudaranya membuat 
peneliti tertarik untuk meneliti mengenai gambaran penerimaan saudara kandung dari penyandang disabilitas intelektual. Penelitan ini akan dilakukan kepada lima orang saudara kandung dari penyandang disabilitas intelektual yang berusia remaja madya.

\section{METODE}

\section{Partisipan}

Dalam penelitian ini karakteristik subjek yang dilibatkan adalah remaja berusia 15-18 tahun (remaja madya) dan memiliki saudara kandung dengan disabilitas intelektual.

\section{Desain}

Penelitian ini merupakan penelitian kualitatif di mana data diperoleh melalui wawancara, observasi, dan catatan lapangan. Data yang terkumpul berbentuk kata-kata atau gambar, sehingga tidak mengunakan angka (Poerwandari, 2011). Penelitian ini juga dikenal sebagai naturalistic inquiry, di mana penelitian ini tidak berusaha untuk memanipulasi konteks penelitian, melainkan melakukan studi terhadap sesuatu fenomena dalam situasi di mana fenomena tersebut ada.

Dengan dasar penelitian kualitatif tersebut maka untuk megetahui gambaran penerimaan saudara kandung dari penyandang disabilitas intelektual memerlukan data-data yang diperoleh melalui observasi dan wawancara serta data yang diperoleh dari berbagai sumber. Penelitian ini menggunakan pendekatan fenomenologi.

\section{Prosedur}

Penelitian ini menggunakan dua tahap. Tahap pertama adalah tahap persiapan, yang meliputi penyusunan pedoman wawancara; penentuan subjek penelitian dengan teknik berfokus pada intensitas atau intensity sampling. Pengambilan sampel berfokus pada intensitas digunakan untuk memperoleh data yang kaya mengenai fenomena tertentu. Sampel bukanlah kasus ekstrim melainkan diperkirakan mewakili fenomena secara intens (Poerwandari, 2011). Tahap kedua adalah tahap pelaksanaan, yaitu pengambilan data lapangan. Pengambilan data dilakukan kepada 5 orang subjek dan lima orang yang dekat dengan subjek.

\section{Instrumen}

Dalam penelitian ini yang digunakan adalah teknik wawancara. Kegiatan untuk memperoleh pengetahuan tentang makna-makna subjektif yang dipahami individu berkenaan dengan topik yang 
diteliti dan bermaksud melakukan eksploransi terhadap isu tersebut, suatu hal yang tidak dapat di lakukan melalui pendekatan lain (dalam Poerwandari, 2011). Metode yang digunakan pada penelitian ini adalah wawancara semi terstruktur dengan sifat wawancara terbuka. Maksudnya adalah peneliti dan narasumber sama-sama mengetahui tujuan dari wawancara. Pada penelitian ini peneliti akan menggunakan panduan wawancara. Panduan wawancara mengacu pada teori KublerRoss (dalam Videbeck, 2010) di mana terdapat lima tahap penerimaan yaitu: (1) denial (menyangkal), merupakan perasaan terkejut dan tidak percaya mengenai apa yang terjadi; (2) anger (kemarahan), merupakan perasaan marah yang dapat ditujukan kepada Tuhan, keluarga, maupun saudaranya sendiri, dan teman; (3) bargaining (perundingan), fase di mana seseorang melakukan perundingan dan meminta kepada Tuhan ataupun nasib untuk mengubah nasibnya atau menunda kemalangannya; (4) depression (depresi), terjadi ketika seseorang benar-benar menyadari kemalangannya menjadi lebih buruk; dan (5) acceptance (penerimaan) terjadi ketika seseorang mulai berdamai dengan kemalangannya. Pedoman wawancara penelitian mengacu pada kelima aspek di atas. Berikut adalah contoh pertanyaan untuk tiap aspek:

Tabel 1

Pertanyaan Per Aspek

\begin{tabular}{ll}
\hline Aspek & Pertanyaan \\
\hline Denial & Sejak umur berapa anda mengetahui kondisi saudara anda? \\
& Bagaimana respons anda saat mengetahui kondisi saudara anda? \\
& Apa yang anda pikirkan ketika mengetahui kondisi saudara anda? \\
& Apakah anda pernah merasa bahwa hadirnya saudara anda, membawa dampak \\
& negatif dalam hidup anda? \\
& Bagaimana cara orangtua menjelaskan kondisi adik anda kepada anda saat itu? \\
& Apakah anda merasa malu dengan kondisi saudara anda yang menyandang \\
& intellectual disability? \\
Anger & Apakah anda pernah marah kepada saudara anda yang menyandang intellectual \\
& disability? \\
& Apa yang membuat anda marah kepadanya? \\
& Bagaimana respons saudara anda ketika anda marah? \\
& Apa yang dilakukan orangtua anda ketika anda marah kepada saudara anda? \\
& Apakah anda pernah marah karena kondisi saudara anda yang menyandang \\
& intellectual disability? \\
Apakah anda pernah merundingkan kondisi atau keadaan adik anda dengan \\
oranglain? \\
Apa saja yang telah anda lakukan untuk saudara anda? \\
Usaha apa saja yang anda lakukan untuk membantu saudara anda? \\
Apa harapan anda bagi saudara anda? \\
\hline Pertanyaan \\
\hline Depression & Menurut anda, apakah kondisi saudara anda yang menyandang intellectual \\
& disability semakin membaik? \\
& Apakah anda pernah merasa tertekan dengan kehadiran saudara anda yang \\
& menyandang intellectual disability? \\
& Apakah anda pernah merasa lelah dengan situasi dan kondisi keluarga anda saat \\
\hline
\end{tabular}




\begin{tabular}{ll}
\hline & ini? \\
Acceptance & Apakah anda sudah menerima kondisi saudara anda yang menyandang intellectual \\
& disability? \\
& Apakah anda menyayangi saudara anda tersebut? \\
Apa anda bersedia bila diminta untuk mengurus saudara anda kelak?
\end{tabular}

Selain menggunakan teknik wawancara, peneliti juga melakukan observasi terhadap subjek selama proses wawancara berlangsung, di mana observasi ini bertujuan untuk melihat komunikasi non verbal yang ditunjukkan oleh subjek selama wawancara dan interaksi subjek dengan peneliti selama proses tersebut.

\section{Teknik Analisis}

Teknik analisis data yang digunakan sebagai berikut: (a) Pengkategorian data, data-data dikategorikan agar tersusun rapi dan sistematis. Dalam penelitian ini pedoman wawancara telah tersusun rapi dan sistematis demi memudahkan peneliti untuk mengolah data informasi yang di lakukan pada saat wawancara; (b) Pengkodean (coding), peneliti melakukan coding terhadap verbatim wawanara. Tahapan ini diawali dengan membaca ulang semua data dan kemudian memberikan tema-tema tertentu yang berguna untuk mempermudah dan memperjelas analisis data; (c) Analisis data (interpretasi), peneliti melakukan interpretasi terhadap data-data dari subjek kemudian mengaitkan dengan teori yang berhubungan dengan topik penelitian sehingga tujuan. Penelitian tercapai. Content analysis menggunakan metode deduktif, yaitu membagi langkah koding dalam tiga bagian yaitu koding terbuka yang memungkinkan kita mengidentifikasi kategorikategori, properti-properti, dan dimensi-dimensinya. Kemudian dilanjutkan dengan koding aksial yaitu mengkoordinasi data dengan cara baru melalui dikembangkannya hubungan-hubungan di antara kategori-kategori atau diantara kategori dengan sub-kategori di bawahnya. Tahap terakhir adalah koding selektif, di mana peneliti menyeleksi kategori paling mendasar secara sistematis, menghubungkan dengan kategori lain dan memvalidasi hubungan tersebut. Dalam penelitian ini peneliti menggunakan triangulasi data di mana dalam penelitian ini peneliti dapat memperkaya informasi melalui triangulasi data serta membuat penelitian ini akurat. 


\section{ANALISIS DAN HASIL}

\section{Karakteristik Subjek}

Tabel 2.

Karakteristik Subjek

\begin{tabular}{|c|c|c|c|c|c|}
\hline & Subjek 1: E & Subjek 2: F & Subjek 3: T & Subjek 4: M & Subjek 5: A \\
\hline Usia & 17 tahun & 17 tahun & 18 tahun & 17 tahun & 17 tahun \\
\hline $\begin{array}{l}\text { Jenis } \\
\text { Kelamin }\end{array}$ & Perempuan & Laki-laki & Laki-laki & Perempuan & Laki-laki \\
\hline Pekerjaan & Pelajar & Pelajar & Mahasiswa & Pelajar & Pelajar \\
\hline Agama & Kristen & Islam & Kristen & Katolik & Islam \\
\hline $\begin{array}{l}\text { Jumlah } \\
\text { Saudara } \\
\text { Kandung }\end{array}$ & 1 (satu) orang & 2 (dua) orang & 2 (dua) orang & 2 (dua) orang & 2 (dua orang) \\
\hline $\begin{array}{l}\text { Anak Ke- } \\
\text { Klasifikasi } \\
\text { disabilitas } \\
\text { intelektual }\end{array}$ & $\begin{array}{l}1 \text { (satu) } \\
\text { Sedang }\end{array}$ & $\begin{array}{l}2 \text { (dua) } \\
\text { Sedang }\end{array}$ & $\begin{array}{l}1 \text { (satu) } \\
\text { Berat }\end{array}$ & $\begin{array}{l}2 \text { (dua) } \\
\text { Sedang }\end{array}$ & $\begin{array}{l}2 \text { (dua) } \\
\text { Ringan }\end{array}$ \\
\hline Beda usia & 3 tahun & 4 tahun & 2 tahun & $\begin{array}{l}1 \text { tahun } \\
\text { bulan }\end{array}$ & 2 tahun \\
\hline
\end{tabular}

\section{Subjek 1}

E mengalami tahap denial yaitu perasaan terkejut dan tidak percaya bahwa dirinya memiliki adik dengan disabilitas intelektual. E juga terkadang merasa malu memiliki adik dengan disabilitas intelektual. Perasaan malu tersebut diakui oleh subjek sebagai dampak negatif hadirnya sang adik dalam kehidupannya.

"Kayak agak sedikit malu gitu sih."

"Cuma cara pandangnya mereka kalau lagi ngeliatin tuh terlalu lama yang bikin saya ngerasa ih kenapa sih kok kayak gitu."

Pernyataan E tersebut menunjukkan bahwa ia merasa risih dengan pandangan orang lain terhadap kondisi adiknya. E juga mengalami tahap anger. Tahap anger merupakan perasaan marah yang dapat ditujukan kepada Tuhan, keluarga, maupun saudaranya sendiri, dan teman. Dapat juga dengan mengabaikan perawatan kesehatan diri.

"Seringlah, sering banget gitu. Apalagi kan karena dia kurangnya itu, dia gak bisa, kita harus lebih mengerti, jadi ya dengan sikap-sikap jahilnya dia gitu. Cuma itu yang masih belom bisa saya kontrol emosi saya gitu."

“...dia itu susah dibilangin” 
Pernyataan-pernyataan tersebut menunjukkan bahwa E mengalami tahap anger di mana perasaan marahnya ditujukan kepada adiknya. Pernyataan E tersebut juga diperkuat oleh pernyataan dari orang terdekat E yaitu teman dekat E. E sering marah kepada adiknya karena adiknya sulit untuk diberitahu.

E juga mengalami tahap bargaining di mana melakukan perundingan dengan orang lain agar saudaranya menjadi seperti anak normal pada umumnya.

"Ya minta penjelasannya gitu. Waktu itu kan saya masih kecil juga, ya nanya apa penyebab dia kok jadi begini, kayak gitu."

"Ya membicarakan sih, kalau anak normal kalau abis sekolah kan kuliah, nah dia ini nanti mau gimana kalau udah selesai sekolah. Gitu sih."

"Tapi nyokap selalu bilang sih sampai saya nikah pun adik harus saya bawa."

"Itu sih masih bingung juga. Ya itu. Susah gitu cerita misalnya juga kalau ke pacar sendiri, mau gak masih nerima kondisi keluarga dengan seperti ini. Gitu sih. Itu yang masih jadi kepikiran juga harus kayak gimana."

E membicarakan masa depan adiknya dengan ibunya. Dan ibunya selalu mengatakan bahwa E harus membawa adiknya bersama dengannya meskipun nanti dirinya sudah menikah.

E juga mengalami tahap depression. Pada fase ini E menyadari bahwa kondisi adiknya tidak membaik dan kondisi keluarganya juga tidak membaik.

"Hal-hal kayak gitu kayaknya udah gak bisa disembuhin"

"Itu sih masih bingung juga. Ya itu. Susah gitu cerita misalnya juga kalau ke pacar sendiri, mau gak masih nerima kondisi keluarga dengan seperti ini. Gitu sih. Itu yang masih jadi kepikiran juga harus kayak gimana."

E masih sulit menerima kondisi adiknya dan merasa bingung mengenai apa yang harus ia lakukan, sementara orangtuanya mengharuskan dirinya merawat adiknya. E belum mencapai tahap acceptance.

"Belum sepenuhnya karena ya itu saya juga masih belum dewasa banget. Ya jadi yaa masih kayak setengah setengah sih."

"Rasa malu, rasa egois itu."

"Egois ya mungkin kalau berumah tangga lebih memilih keluarga dari pada adik sendiri itu sih."

E masih belum dapat menerima kondisi adiknya sepenuhnya karena masih merasa malu dan dirinya masih merasa belum cukup dewasa. E juga merasa bahwa dirinya egois karena sejujurnya 
dirinya keberatan bila harus membawa adiknya tinggal bersama dengannya kelak. Ia merasa akan lebih memilih berkeluarga sendiri dan lebih memperhatikan keluarganya daripada adiknya.

\section{Subjek 2}

F mengalami fase denial di mana terkejut dan tidak percaya bahwa dirinya memiliki adik dengan disabilitas intelektual. Pada fase ini F memikirkan mengapa dirinya memiliki adik yang berbeda dengan anak normal lainnya. Muncul perasaan sedih pada diri F ketika mengetahu kondisi adiknya.

"Pernah, pas masih kecil, kayak kurang nerima gitu. Kenapa adik saya kayak gini?

Gak seperti orang normal."

"Ya pertama mah sedih. Sedihnya kok beda sama yang lain..."

"Khawatirnya ya takutnya kurang terjamin dan kurang mandirinya gitu...."

F juga mengalami tahap anger. Anger (kemarahan), merupakan perasaan marah yang ditujukan antara lain kepada Tuhan, keluarga, maupun saudaranya sendiri, dan teman. Dapat juga dengan mengabaikan perawatan kesehatan diri. dalam hal ini $\mathrm{F}$ merasa kesal terhadap adiknya karena diperlakukan istimewa oleh orangtuanya. F sering melakukan protes kepada orangtuanya mengenai hal tersebut.

"Iri mah gak sih. Biasa. Paling juga kesel doang."

“...Ya kesel lah kok adik gw dibeliin. Adik gw diturutin, gw gak...”

"Ya pernah sih kalau protes mah. Paling juga ma, kok si adik ini, kok aku gak?”

Setelahnya $\mathrm{F}$ memasuki tahap bargaining yang merupakan tahap di mana $\mathrm{F}$ melakukan penawaran kepada Tuhan agar diberikan adik dengan kondisi normal. Dalam tahap ini juga $\mathrm{F}$ melakukan perundingan dengan oranglain agar saudaranya dapat bertumbuh dan berkembang selayaknya anak normal. F melakukan perundingan dengan orangtuanya dan iapun turut membantu adiknya dalam belajar, agar adiknya dapat membaca dan menulis.

"Ya lebih baik kita berbuat apa ya, ya buat adik saya lebih maju, lebih normal, ya lebih bisa kayak orang-orang, bisa mengikuti seperti biasa."

“...Kalau saya udah selesai belajar, saya ajarin tuh dia belajar, kayak ibarat nulis, baca, paling kayak gitu. Kalau misalnya ada PR, sebisa mungkin saya dulu PR saya, saya selesain, nanti ada PR adik saya, saya bantu." 
F tidak mengalami tahap depression. Pada tahap depression seseorang benar-benar menyadari keadaan saudaranya dan keadaan dirinya dan keadaan keluarganya yang tidak baik menjadi lebih buruk. Namun F justru sebaliknya. Lambat laun, F melihat bahwa adiknya sudah seperti anak normal, dapat diajak bermain bersama, cukup mampu bersosialisasi dengan orang lain.

\footnotetext{
"Sering malah ikut main juga dia. Jadi dia suka ikut nimbrung gitu main."

"Masalahnya adik saya juga perilakunya kayak orang normal."

"Tapi kalau sikap atau perilakunya itu, kalau menurut saya ya udah mendekati normal. Dia bersosialisasinya udah bagus.”
}

Hingga saat ini $\mathrm{F}$ sudah mencapai tahap acceptance yaitu tahap di mana $\mathrm{F}$ sudah menerima kondisi adiknya sepenuhnya. Seseorang dikatakan telah mencapai acceptance jika ia sudah dapat menunjukkan sikap positif dan menerima kekurangan saudaranya. F belajar memahami bahwa adiknya memang memiliki perbedaan dengan anak lainnya, dalam hal aktivitas sehari-hari adiknya masih perlu dibantu, namun $\mathrm{F}$ bersedia membantu adiknya tanpa mengeluh, dan seringkali merasa terhibur dengan tingkah laku adiknya.

"Udah. Udah sekian berapa lama ya sudahlah menerima."

"Seperti biasa aja seperti orang normal aja, gak ada dampak negatif. kalau positif sih ya ada. Adanya ya kadang-kadang ngehibur, kalau lagi bete, dia ada tingkah laku yang konyol. Yang bikin terhiburlah ketawa.

"Sayang, walaupun kayak gini juga tetep adik kandung sih."

\section{Subjek 3}

Ketika mengetahui kondisi adiknya yang terlahir dengan kondisi disabilitas intelektual, T bersikap biasa saja. Ia tidak menyangkal kondisi adiknya dan menerima adiknya apa adanya. Ia juga tidak pernah berpikir mengapa dirinya memiliki adik berkebutuhan khusus.

\footnotetext{
"Biasa saja..."

"Orangtua sih waktu itu ga sempat memberitahu, Cuma karena T sudah melihat adik

T kayak gitu, oh ya udah itu adik gw gitu."

"Gak pernah juga."
}

T juga tidak mengalami tahap anger. Ia tidak pernah menyalahkan oranglain atas kondisi adiknya ataupun menyalahkan orangtuanya atas perlakuan yang istimewa terhadap adiknya. Ia bahkan tidak pernah marah kepada adiknya.

\footnotetext{
"Gak pernah. Apalagi marah, gak pernah"
} 
"Karena banyak orang yang nemuin saya dia bilang, hebat ya kakaknya bisa jagain adiknya sampe kayak gini, bisa sesabar ini."

T melalui tahap bargaining di mana ia berupaya agar kondisi adiknya membaik dan dapat lebih mandiri. Banyak hal yang dilakukan oleh T untuk adiknya.

"Saya selalu ada disamping dia. Jadi setiap dia diajarin begini, sayapun ngikutin, kalau dia diajak jalan, sayapun jalan gitu."

"Itu saya sama mama saya, karena papa saya lagi sibuk yang lain, yang gak bisa ditinggal."

"Terkadang saya merasa ingin berganti saja posisi dengan adik saya, kadang kasihan ngeliat dia susah ini itu."

Setelah tahap bargaining, yang dialami oleh $\mathrm{T}$ adalah tahap depression di mana dirinya merasa lelah dengan rutinitasnya yang harus mendampingi adiknya dalam terapi. Ia tidak dapat seperti anak-anak lainnya yang menghabiskan waktu dengan bermain. Dalam tahapan ini, T terkadang merasa iri juga dengan teman-temannya yang tidak harus membatu merawat adiknya atau sanak saudara lainnya yang berkebutuhan khusus, ia juga ingin melakukan aktivitas lain bersama teman-temannya namun seringkali dibatalkan karena harus menemani adiknya belajar, atau pergi ke tempat terapi.

"Pernah, waktu itu sih pernah. Karena jarak tempuh yang saya lakukan itu dari Karawang ke Jakarta. Itu setiap hari dilakuin karena waktu itu masa terapi,.."

"Ya ngeluh, cape kan. Duh cape nih kayak gini. Kan waktu itu gak bisa main kan sama teman-teman. Ngeliatin orang kayaknya enak juga nih main kan. Tapi saya harus ngurusin adik."

Semakin bertambah usia, T semakin dapat mencapai tahap acceptance. Ia sudah menerima kondisi adiknya yang menyandang disabilitas intelektual dan bahkan dirinya dapat menjadikan kondisi adiknya sebagai penyemangat dalam hidupnya. $\mathrm{T}$ bertekad untuk menjadi orang yang sukses di masa depan agar dapat membantu menafkahi adiknya. T sangat menyayangi dan menerima kekurangan adiknya.

"lebih dari 100\% kayaknya."

"Arti adik saya bagi saya itu adalah semangat. Maksudnya itu kalau saya gak bisa sukses, saya ga bisa biayain dia kedepannya..."

"Untuk itu sih pasti bersedia." 


\section{Subjek 4}

Saat M mengetahui kondisi adiknya, respons yang diberikan oleh $\mathrm{M}$ adalah biasa saja. Ia tidak merasa malu, tidak juga berpikiran mengapa dirinya diberi adik yang menyandang disabilitas intelektual. M tidak mengalami tahap denial.

"Responnya ya, karna aku masih anak kecil kali ya, jadi kayak oh yaudah, kayak gitu loh."

"Malu sih gak pernah sih aku ngerasa malu, karena udah biasa kali ya, terus juga udah ngerti dari kecil, bodo amat sama orang ngomong apa, orang ngomong apa. Toh dia juga biarin aja gitu loh."

"Gak pernah, sama sekali gak pernah."

Namun M merasa sedih dan marah jika ada oranglain yang membicarakan kondisi adiknya dibelakangnya. Ia tidak suka kondisi adiknya menjadi bahan candaan ataupun bahan pembicaraan. M akan langsung marah kepada orang tersebut. Hal ini dapat menunjukkan bahwa M mengalami tahap anger. Anger (kemarahan) ditujukan kepada orang lain yang dirasakan berbuat tidak baik kepada adiknya, baik dalam bentuk perbuatan seperti sengaja membuat adiknya terjatuh, ataupun dalam bentuk perkataan yang menghina kemampuan adiknya.

"Tapi aku malah sedihnya kalau misalnya orang lain yang jatuhin dia gitu loh."

"Sedih, teruskan kayak mau nangis gitu, terus ya aku bentak dianya ..."

M selalu memperlakukan adiknya seperti anak normal, jika adiknya salah maka ia akan mengajarkan yang benar, $\mathrm{M}$ juga selalu membantu adiknya mengerjakan pekerjaan sekolahnya.

"Cuma ya aku sekedar nanya aja, ma kekurangannya itu apa sih gitu kan, oh emang gangguan mental dari dalem kandungan."

“.... Kayak memang akupun mau melakukan yang lebih buat adikku gitu loh. Jadi kalaupun orangtuaku mau melakukan yang lebih, ya gak apa-apa, karena akupun kayak gitu ke dia..."

“...misalnya dia minta tolong atau apa, walaupun aku bercandain gak mau, gak mau, tapi akhirnya tetep aku bantuin...”

M tidak mengalami tahap depression. Dirinya menyadari bahwa kondisi adiknya semakin membaik. Ia merasa adiknya sudah seperti orang normal. Ia pun memperlakukan adiknya layaknya anak normal. Ia juga tidak pernah merasa lelah memiliki seorang adik penyandang disabilitas intelektual. 
"Karena diapun sudah seperti orang normal yang kukenal."

"Terus abis itu juga sekarang itu kayak aku merasa adikku tuh normal gitu loh.

Karena dia bisa ngelakuin apa aja yang orang normal lakuin.”

"Jadi kayak perlakuan orang normal bisa dia lakuin gitu loh, jadinya asik-asik juga."

Hingga saat ini, M sudah mengalami tahap acceptance. Tahap acceptance adalah tahap di mana seseorang sudah dapat menerima kekurangan saudaranya dan ditunjukkan dengan sikap positif kepada saudaranya. M berusaha untuk selalu sabar dalam menghadapi perilaku adiknya yang terkadang tidak dapat ditebak, ia juga berusaha sabar dalam menghadapi respons dari lingkungan sekitar terhadap kondisi adiknya. M mau menerima adiknya apa adanya, ia juga menyadari bahwa di dunia ini banyak orang lain yang mengalami kondisi seperti dirinya dan tetap mampu bertahan dan mengusahakan yang terbaik bagi keluarganya. M berusaha melihat kelebihan dari adiknya, tidak hanya fokus pada kekurangan yang dimilikinya.

\footnotetext{
"Sudah."

"Kita berdua tuh sama orangnya, kalau misal ke adik ya sayang"

"kalau aku sih gak keberatan."

"Seru punya adik kayak gini."

"Terus apa ya, buat kita makin kayak sabar, kayak makin baik kedepannya, jadi gak sombonglah sama orang gitu-gitu."
}

\section{Subjek 5}

A mengalami tahap denial di mana dirinya menolak kondisi adiknya dan merasa malu memiliki adik yang menyandang disabilitas intelektual. A merasa malu dengan lingkungan sekitarnya, terutama teman-teman sebayanya, ia takut diejek karena memiliki adik berkebutuhan khusus yang berperilaku berbeda dari anak-anak lainnya.

"Malu. Iya malu sih sebenernya."

"Karena apa ya. Karena kondisinya dia sih.”

Selain denial, A juga mengalami tahap anger. Di mana pada tahap ini A merasa kesal dan marah karena kondisi adiknya. Kondisi adiknya menyebabkan adiknya diperlakukan istimewa oleh kedua orangtuanya. A merasa iri dan kesal serta ingin memberontak. Tak jarang dirinya melakukan protes kepada kedua orangtuanya.

"Ya kesel ajalah."

"Ya gara-gara itulah. Semuanya diturutin. Udah gitu orangnya dia pelit dia."

"Ya protes sering." 
"Ya protes. Dikasih mulu dia. Kakaknya gak dikasih."

"Ya pengen ngeberontak gitu"

A juga mengalami tahap bargaining di mana ia berusaha agar adiknya menjadi seperti anak normal. Ia membantu mengajari adiknya mengenai hal-hal baik. A pernah juga berdoa kepada Tuhan agar kondisi adiknya semakin lama semakin membaik, agar tidak perlu lagi diperhatikan secara istimewa oleh orang-orang disekitarnya terutama oleh kedua orangtuanya. A seringkali merasa kondisi adiknya sudah tidak dapat membaik, emosi adiknya tidak dapat diubah atau dikendalikan.

"Pernah. Gak bisa. Kalau misalnya gak diturutin marah-marah dia. Kadang ngelawan sama orangtuanya. Iya kayak gitu."

"Ya ngajarin dia gitu, ngasih tahu yang bener. Yang baik-baik gitu."

"Ya pengen bisa. Bisa prihatin gitu. Kalau lagi kayak gini minta uang ke orangtua jangan banyak-banyak. Prihatin gitu."

"Berdoa aja sama Tuhan, minta gitu supaya makin baik, biar adil perhatiannya"

"Pernah. Gak bisa. Kalau misalnya gak diturutin marah-marah dia. Kadang ngelawan sama orangtuanya. Iya kayak gitu."

A juga masih belum menerima kondisi dan kekurangan yang dimiliki oleh adiknya. Ia masih merasa malu dengan kondisi adiknya saat ini dan menganggap kehadiran adiknya memberikan dampak negatif dalam kehidupannya. A belum mencapai tahap acceptance.

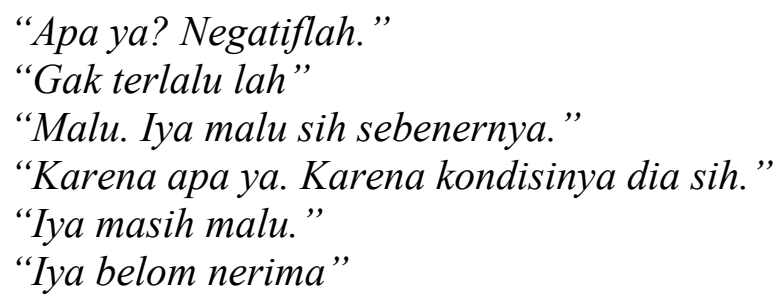

\section{DISKUSI}

Menurut Kubler-Ross (dalam Videbeck, 2010), terdapat lima tahap penerimaan antara lain denial di mana pada tahap ini seseorang merasa terkejut dan tidak percaya mengenai apa yang terjadi. Dalam Gargiulo (1985) disebutkan bahwa denial ditandai dengan rasa takut dan malu serta menolak kehadiran anak dengan disabilitas intelektual. Subjek 1 (E) dan subjek 5 (A) mengalami tahap denial di mana $\mathrm{E}$ dan A merasa malu dengan kehadiran saudara mereka yang menyandang 
disabilitas intelektual. E dan A merasa sulit untuk memperkenalkan saudara mereka yang menyandang disabilitas intelektual kepada teman-teman mereka.

Dalam Gargiulo (1985) disebutkan bahwa perasaan anger merupakan hambatan dalam menuju acceptance. Anger dapat ditunjukkan dalam dua cara, dapat ditunjukkan dengan pemikiran “mengapa harus saya?" atau dapat pula ditunjukkan kepada orang lain (menjadikan orang lain sebagai pelampiasan). Subjek E menunjukkan anger dalam keduanya. Ia seringkali berpikir mengapa dia yang diberikan adik dengan disabilitas intelektual. Selain itu ia juga melampiaskan kekesalannya kepada adiknya. Pada subjek F dan A cenderung menunjukkan anger dalam bentuk protes kepada orangtuanya. Sementara subjek T tidak menunjukkan tahap anger. Subjek M, menunjukkan tahap anger kepada orang lain secara langsung, terutama saat orang lain berbuat hal yang tidak baik kepada adiknya baik secara fisik maupun verbal.

Bargaining fase di mana seseorang melakukan perundingan dan meminta kepada Tuhan ataupun nasib untuk mengubah nasibnya atau menunda kemalangannya (Videbeck, 2010). Dalam fase ini, seseorang berharap kepada Tuhan, dokter, ataupun orang lain untuk membuat anak dengan disabilitas intelektual menjadi normal (Gargiulo, 1985). Kelima subjek mengalami tahap bargaining di mana kelimanya berdiskusi dengan orangtuanya mengenai kondisi saudaranya, membantu dan berusaha agar adiknya menjadi anak normal, bahkan subjek 3 ikut mendampingi adiknya dalam proses terapi.

Depression merupakan tahap di mana seseorang benar-benar menyadari kemalangannya menjadi lebih buruk (Videbeck, 2010). Subjek E, dan subjek A merasa bahwa kondisi adiknya sudah tidak dapat diubah. Mereka merasa adiknya memang tidak dapat berkembang dengan baik atau bahkan belajar mengontrol emosi mereka. Mereka merasa keadaan keluarga mereka juga semakin memburuk dengan hadirnya sang adik. Sementara subjek T mengalami tahap depression ditunjukkan oleh perasaan lelahnya untuk terus mendampingi adiknya. Ia merasa adiknya membuat ia tidak dapat seperti anak lainnya yang dapat bermain sepulang sekolah.

Fase terakhir adalah acceptance. Pada fase ini, seseorang dapat menerima kekurangan maupun kelebihan dari anak yang menyandang disabilitas intelektual (Gargiulo, 1985). Subjek yang telah mencapai fase ini adalah subjek F, subjek T, dan subjek M. Ketiga subjek ini sudah dapat menerima kondisi adiknya bahkan bersedia untuk menjaga dan mengurus adiknya di masa mendatang sekalipun mereka telah berkeluarga.

Menurut Hendriani, Handariyati, dan Sakti (2006) terdapat beberapa faktor yang memengaruhi penerimaan saudara kandung antara lain adanya komunikasi yang baik dalam keluarga, adanya informasi mengenai kondisi anak dan adanya pemahaman mengenai disabilitas 
intelektual, kesiapan memiliki saudara baru. Hal ini biasanya dialami oleh anak pertama. Faktor lainnya adalah persepsi yang positif terhadap anak dengan disabilitas intelektual. Subjek E dan subjek A belum mencapai tahap acceptance dikarenakan adanya persepsi negatif mengenai anak dengan disabilitas intelektual dari orang sekitarnya serta komunikasi yang kurang baik didalam keluarganya.

\section{SIMPULAN DAN SARAN}

\section{Simpulan}

Terdapat 3 subjek yang telah mencapai tahap acceptance yaitu, F, T dan M. Sementara itu E dan A belum mencapai tahap acceptance. Subjek yang dapat mencapai tahap acceptance dipengaruhi oleh persepsi positif dari diri mereka terhadap adiknya yang menyandang disabilitas intelektual, komunikasi dalam keluarga dan pemahaman serta pengetahuan mengenai kondisi adik mereka yang menyandang disabilitas intelektual. Sementara subjek E dan A belum dapat mencapai tahap acceptance dikarenakan kurangnya komunikasi dalam keluarga, dan persepsi negatif subjek maupun orang lain terhadap kondisi adiknya yang menyandang disabilitas intelektual.

\section{Saran Teoretis}

Dalam penelitian ini masih banyak kekurangan yang dimiliki, untuk itu bagi peneliti selanjutnya yang ingin melakukan penelitian dengan variabel yang sama diharapkan dapat lebih memperdalam teori-teori yang digunakan. Peneliti juga menyadari dalam penelitian ini, sumbersumber dan referensi yang digunakan masih sangat kurang, oleh kerena itu untuk peneliti selanjutnya sebaiknya menggunakan lebih banyak lagi sumber-sumber dan referensi yang akurat terkait dengan permasalahan yang diangkat.

\section{Saran Praktis}

Bagi yang memiliki saudara kandung penyandang disabilitas intelektual, disarankan untuk memperbanyak interaksi dengan saudara kandungnya tersebut agar lebih memahami kondisi mereka. Selain itu disarankan untuk berdiskusi atau mencari informasi mengenai disabilitas intelektual sehingga dapat mengetahui apa saja yang dibutuhkan oleh penyandang disabilitas intelektual untuk dapat bertumbuh dengan baik dan dapat lebih menerima kondisi mereka.

Bagi orangtua dari subjek penelitian ini, disarankan untuk lebih sering mengajak anaknya yang tidak menyandang disabilitas intelektual untuk bertukar pikiran dan sharing apa yang dirasakan mengenai saudaranya yang menyandang disabilitas intelektual baik yang baik maupun 43 
yang buruk. Selain itu dapat juga mencari aktivitas menyenangkan yang melibatkan seluruh anggota keluarga.

Bagi orangtua yang memiliki anak kandung dua atau lebih dan salah satunya menyandang disabilitas intelektual, disarankan untuk memberikan pengertian mengenai kondisi anak yang menyandang disabilitas intelektual kepada saudaranya yang normal sejak masih kecil. Sehingga saudaranya yang normal memahami bahwa kondisi saudara mereka berbeda dan membutuhkan perlakuan khusus.

\section{REFERENSI}

Algozzine, B \& Ysseldyke, J. (2006). Teaching students with mental retardation a practical guide for every teacher. California, CA: Corwin Press.

American Psychiatric Association [APA]. (2013). Diagnostic and statistical manual of mental disorders (5th ed.). Washington, DC: American Psychiatric Publishing.

Aytekin, C. (2016). Siblings of Disabled Children: A General Overview in terms of Academic Studies. International Journal of Innovation and Applied Studies, 16(3), 522-527.

Gargiulo, R. M. (1985). Working with parents of exceptional children: A guide for professionals. Boston, MA: Houghton Mifflin.

Hendriani, W., Handariyati, R., \& Sakti, T. M. (2006). Penerimaan keluarga terhadap individu yang mengalami keterbelakangan mental. INSAN, 8(2), 100-111.

Kutner, L. (2016). When a sibling is disabled. Ditemu kembali dari http://psychcentral.com/lib/when-a-sibling-is-disabled/.

Lisnawati, L., Shahib, M. N., \& Wijayanegara, H. (2014). Analisis keberhasilan terapi bermain terhadap perkembangan potensi kecerdasan anak retardasi mental sedang usia 7-12 tahun. $M K B, 46(2), 73-82$.

Medina, J. (2016). Intellectual disability (mental retardation) symptoms. PsychCentral. Ditemu kembali dari https://psychcentral.com/disorders/mental-retardation-symptoms/

National Dissemination Center for Children with Disability [NICHCY.] (2017). Children with disabilities: understanding sibling issues. Ditemu kembali dari http://www.ldonline.org/article/6054/

Poerwandari, E. K. (2011). Pendekatan kualitatif untuk penelitian perilaku manusia. Jakarta: LPSP3 UI.

Videbeck, S. L. (2010). Psychiatric-mental health nursing (5th ed.). China: Wolters Kluwer Health. 